\title{
PRIMARY WORKING OF SUPERALLOYS
}

\author{
R.P. Daykin and A.J. DeRidder \\ Ladish Co., Cudahy, Wisconsin
}

An appropriate keynote for this conference session lies with the thought of "a better industry through better use of better R\&D".

The recent months have not been overly kind to the specialty metals industry. While the trend toward more specialization in alloys for many individual applications continues, corporate funds to advance this work have been harder to get. The aerospace base on which we have been largely dependent in the past has shrunken sharply. When industry most needs the benefits of R\&D, dollars are least available. In the primary working field, for example, to accommodate the material needs for higher engine performance now being demanded, stronger superalloys exist with higher temperature capabilities, but many are considered to be unforgeable. Therefore, we must find ways to forge what has, in the past, been considered to be unforgeable if we are to have the best jets and these ways must be found with less money.

We must properly react to this business climate by trying to get more useful R\&D for the dollar. This means more emphasis is being placed on shorter range goals of practical and, hopefully, profitable applications. It not only means that R\&D must be useful, but also that these developments must be used. We believe that this conference has been well planned to provide an important forum for interchange of new ideas which can speed the often time-consuming task of putting development to profitable commercial use. The interplay here between the material producers and the users is especially valuable toward this end.

\section{Goals}

In tune with our keynote theme for primary working of superalloys, we call for an objective re-examination of each basic element in the primary working process to define important goals, identify problems, and direct significant development, accordingly. Not only must we find ways to work the unworkable alloy, but we must emphasize application of controlled processing and quality control procedures to obtain better structural integrity and to establish more economical and efficient production methods. Hot working emphasizes the use of controlled processing to achieve goals of structural integrity, high strength, fracture toughness, long life, and uniformity of forged, extruded and rolled wrought products. Complete attainment of these goals is inextricably interwoven with the qualities of the material being worked as inherited from the melting or powder process. Other sessions are of great interest to us in this area. We have certain concerns in these areas which we will touch on now.

\section{Ingot Structure}

During solidification of cast high-temperature alloys, an inherent dendritic segregation of the age-hardening elements occurs. Depending upon the particular alloy chemistry and ingot melting practice, various degrees of severity can be observed in microstructures that are selectively etched. In Figure 1, the lighter-appearing areas have solidified from the melt first and at a lower concentration of age-hardening elements, such as aluminum and titanium. The relatively higher aluminum and titanium content in the darker areas results in a larger and more thermally stable gammaprime hardening precipitate.

Titanium carbides and other intermetallic particles are concentrated in the dark areas. Either or both forgeability and mechanical property problems can be associated with heavy concentrations of inter. metallic constituents when heavy dendritic segregations occur. Generally, alloys with a higher titanium and aluminum content are most prone to this condition. The conversion of ingot to billet modifies the interdendritic microsegregation by diffusion and recrystallization. However, the affects of the microsegregations have been found to persist even after substantial deformations in certain of the more alloyed compositions. Forging reduction aligns the dendritic pattern, into parallel bands, commonly referred to as "banding" such as illustrated in Figure 2. The difference in titanium and aluminum content between the microsegregations produces the affect of two separate alloys which can drastically affect mechanical property response 
such as transverse ductility and tensile strength as shown in Figure 3 and 4 .

The loss of tensile strength and ductility can also be associated with primary titanium carbide segregation when preferentially located in tensile specimens as shown in Figure 5 .

The ability to forge high-temperature alloys depends to a significant extent on the degree of material uniformity. The presence of stable intermetallics such as carbides, can initiate the formation of minute ruptures which can be then carried through into the final forged and machined product, causing internal or surface defects, as shown in Figure 6. In severe cases, the ruptures continue to develop during the forging operation to a point where they will scrap the forging.

Decreasing forging temperatures, as well as reducing the rate of reduction during forging, contributes to improved forgeability. Segregations that are present in the ingot are generally carried through, to some degree, into the forged configuration. Their effects on forgeability depend on the degree and on the inherent plasticity characteristics of the alloy involved at various temperatures, strains, and strain rates.

Specialty alloy melters have made many important contributions through melting and solidification developments toward the manufacture of a more uniform product with less segregation.

Significant steps have also been taken toward the reduction of the degree of segregation through the development of diffusion heat treatments. These are generally applied to the cast ingot product prior to conversion to any wrought form. This practicc is commonly referred to as "homogenization." (Figure 7).

\section{Micro Carbide Rating}

A method for micro rating relative to superalloy cleanliness of billets or bars has been developed by our company. We believe it has provided a better language of communication from producer to user for critical applications. Various configurations and degrees of stable intermetallics generally occurring as carbides, have been categorized in a chart form (Figure 8) with an associated system of notation for convenience of reference. The accommodation of various alloys to carbides varies. The presence of carbides also vary with the alloy. Individual part applications, depending on the stresses to which each is exposed, can also vary in their tolerance to various carbide conditions. Therefore, the chart does not define acceptance limits since these will vary with alloys and applications.

\section{Ingot Conversion}

In manufacturing superalloy forgings, we have seen an increasing emphasis on improved microstructural control. Specific structures have been identified in selected compositions to be associated with im. proved fatigue or fracture toughness, for example. Accordingly, the forger has been improving his understanding of strain-temperature relationships to produce these structures while progressively shaping the raw material most economically into shape from which the final component can be produced. He has also been improving his controls to most consistently provide the relatively narrow band of deformation conditions conducive to property and uniformity optimation. The structure of the raw material is not often converted to the final desired structure in a single step. It is built up incrementally in a series of manufacturing operations, each carefully planned and contralled.

The conversion of raw ingots to forging billets, accordingly, has taken on a new sophistication. No longer is a large ingot reduced to smaller diameters simply because the small diameter is needed to make a particular sized forging. Rather, it is now seen as the first important deformation processing step in manufacturing a particular structure through the opportunities for reduction it provides. More emphasis is, accord. ingly, being placed on macrostructural uniformity of forging billets. In some cases, redundant working operations can be involved to provide starting stock with best uniformity and structural refinement for a particular forging.

\section{Closed Die Forging}

In the manufacturing sequences for the final forgings, most often sequences of several closed die operations are involved to progressively shape the metal and simultaneously provide the regulated working required for structural development. By manipulating appropriate hot working above the gamma-prime solvus and warm working below it, the alloy is progressively recrystallized and/or warm strained to achieve the best end effect.

In achieving the final structure by such deformation processing, the details of the temperature and degree of metal movement locally throughout the entire cross section of the forging must be carefully established and regulated. All the properties of heat resisting alloys change drastically with small 
differences in:

1. The forging temperature at any particular point.

2. How much the metal is moved at that temperature and,

3. How fast it is moved.

The force requirements to move the metals also vary with the above things and are of basic importance in establishing proper hammer or press size. Die design can be critical in producing a closed die superalloy forging with a high degree of structural uniformity throughout its cross section. Underworked areas lead to areas within the forging with excessively coarse and generally embrittled grain structure. Overworked areas can result in areas which are too fine for certain desired high temperature responses in the final application. While die design still largely relies on the intuitive skills of experienced forging engineers, model studies have been employed to assist in certain specialized problems. Here gridded or laminated model materials, such as gelatin or clay, are deformed in subscale two or three dimensional dies to establish the cross-sectional strain dis. tributions between preparing operations or from a closed die prepared shape to the final forging configuration. This slide shows an example of this work (Figure 9).

\section{Powder Metallurgy}

Recent powder metallurgy developments in superalloys have been encouraging toward the realization of the long-sought goal of this process toward helping to solve some of the problems such as we have been discussing here in uniformity and structurall development. Certainly, the segregation in a powder particle should be a lot less than in a large ingot. Also, fewer working steps must be involved for purely grain refinement since the material is initially produced in an extremely finegrained form. However, the industry has been plagued for a long time with lack of availability of suitable quality powder products at economics compatible with what customers are willing to pay for the final effect. A number of sources have now moved to solve the quality problem with considerable success. With new powder facilities and consolidating processes which have been installed recently, there is good promise for favorable economics. Some of this work has been tied in with hot-die-forging ultrafine grained material to sophisticated final forged contours with good results. Powder promises to spawn a new family of superalloys specifically adaptable to this process. We feel these developments will be teamed with matching forging developments to provide the range of structures and, therefore, properties of which the alloy is capable.

Through forging, or deformation processing, within a specific alloy system, the best tradeoffs between strength, ductility, toughness, and fatigue is achieved.

\section{Conclusion}

Several examples of useful thought and developments within the areas which we have discussed are being presented in this session. They focus on measurements and mechanisms of hot working and hot workability of some of the most popular alloys of current interest. They well exemplify work being done in this interesting area. They properly dwell on optimization of existing systems of melting, solidification, thermal mechanical processing, and heat treatment for presently established alloys. They help us to have a better industry through better use of better R\&D. We are sure by advancing our understanding they will raise new questions stimulating more work, more effort, and this will continue to advance our primary working capabilities further. 


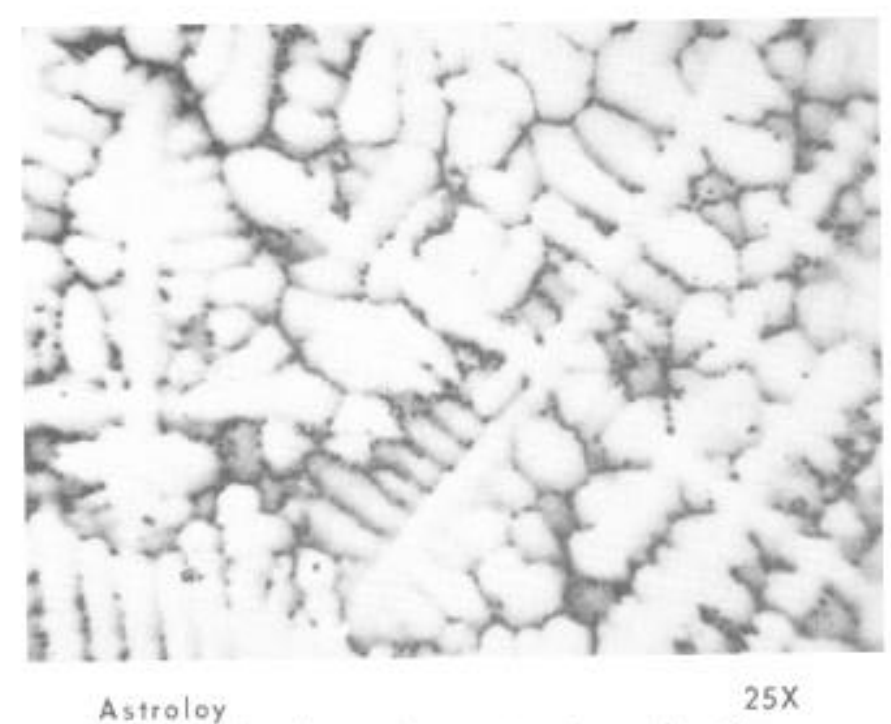

Typical dendritic ingot structure showing large gammo prime aging precipitate and titanium carbide particles in dark etching areas.

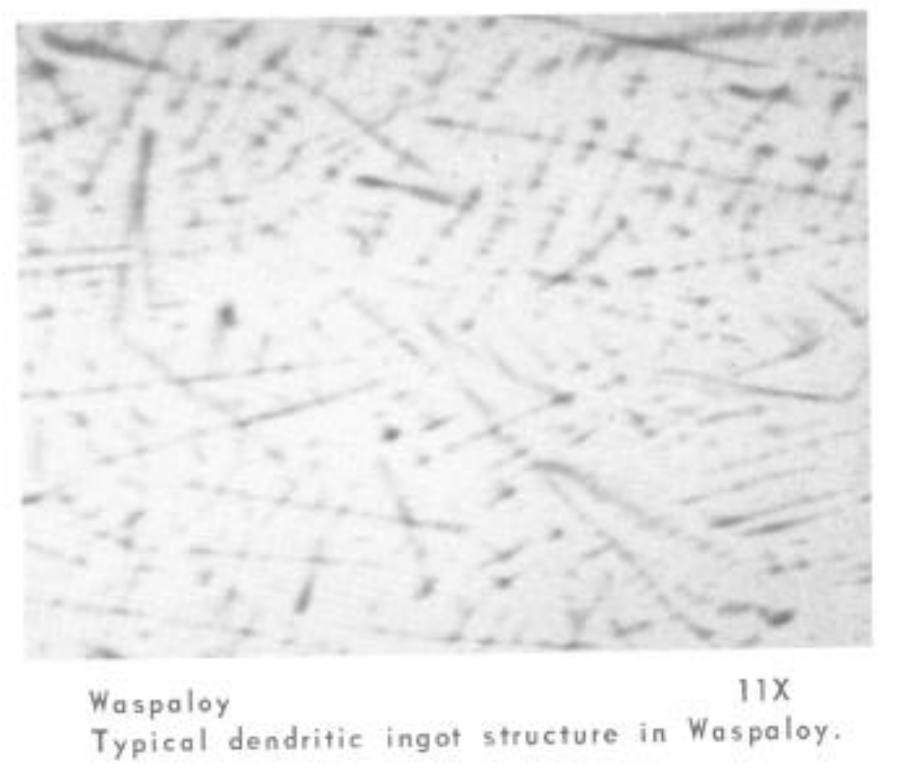

FIGURE 1 

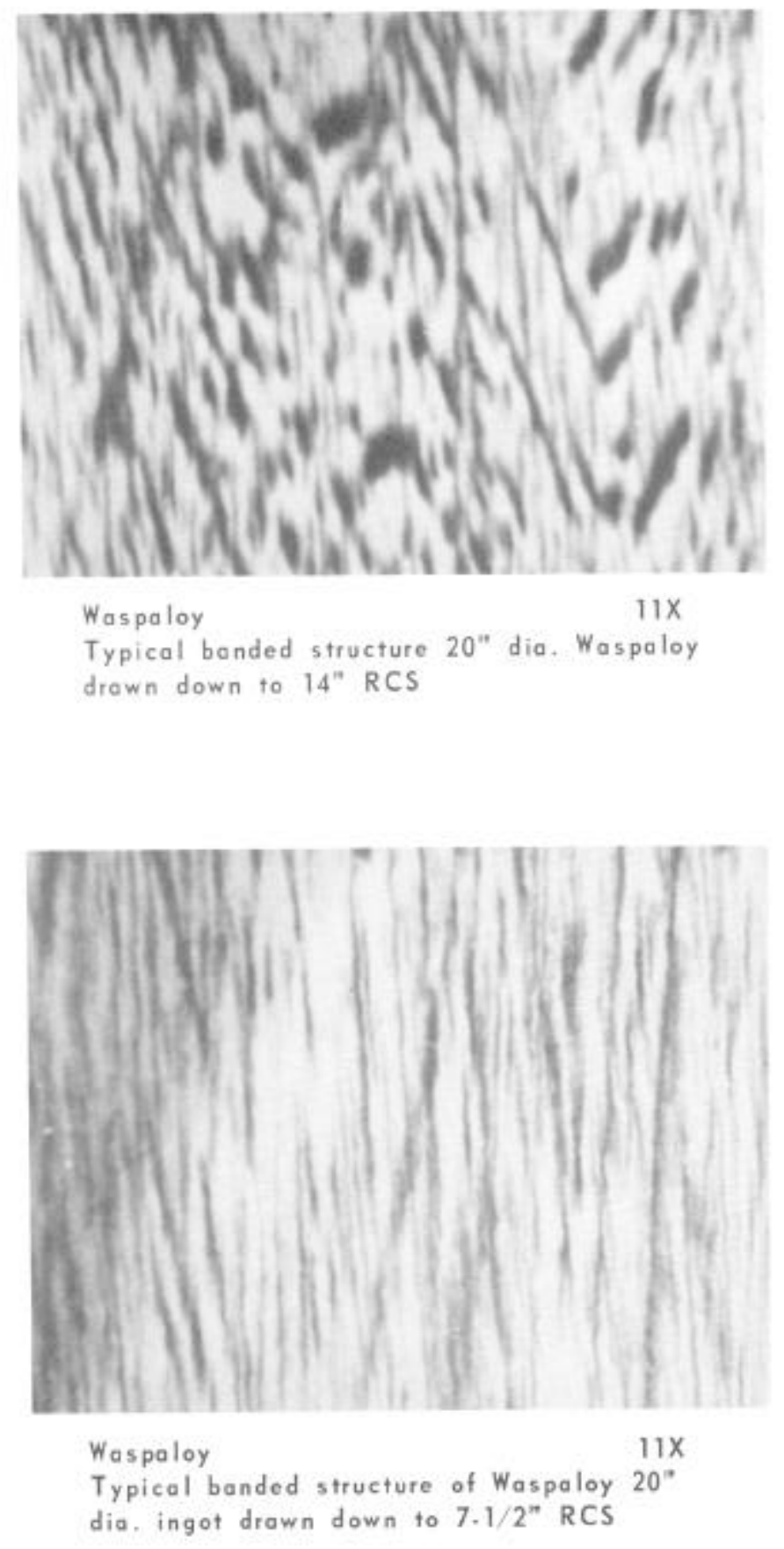

FIGURE 2 


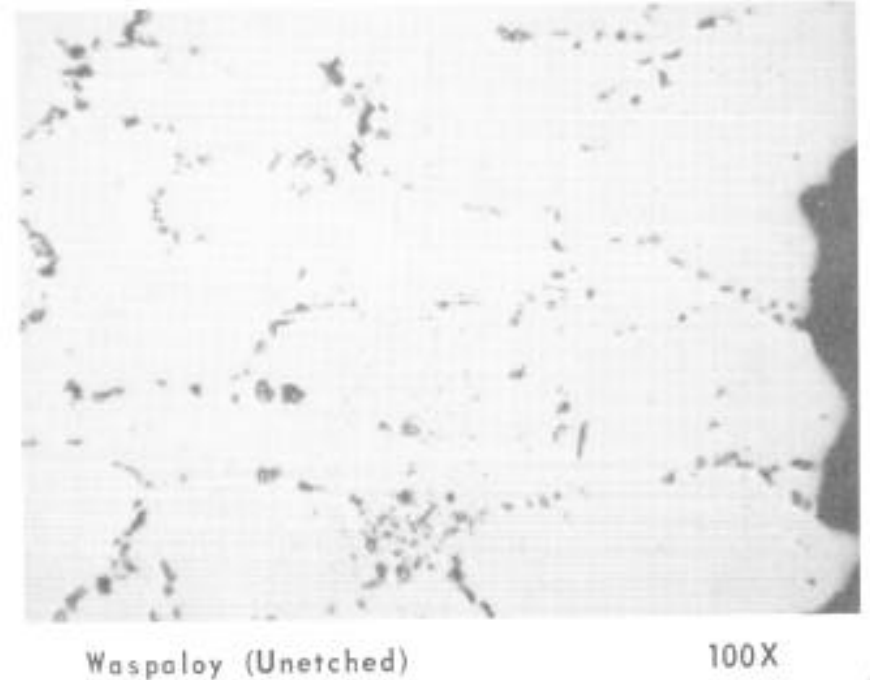

Cluster of titanium carbides locoted at fracture promoted low tensilo ductility response:

$\frac{\text { Y.S. }}{146,000} \quad \frac{\text { T.S. }}{184,000} \quad \frac{\% \text { EI. }}{9.0} \quad \frac{\% \text { R.A. }}{16.3}$

FIGURE 3 


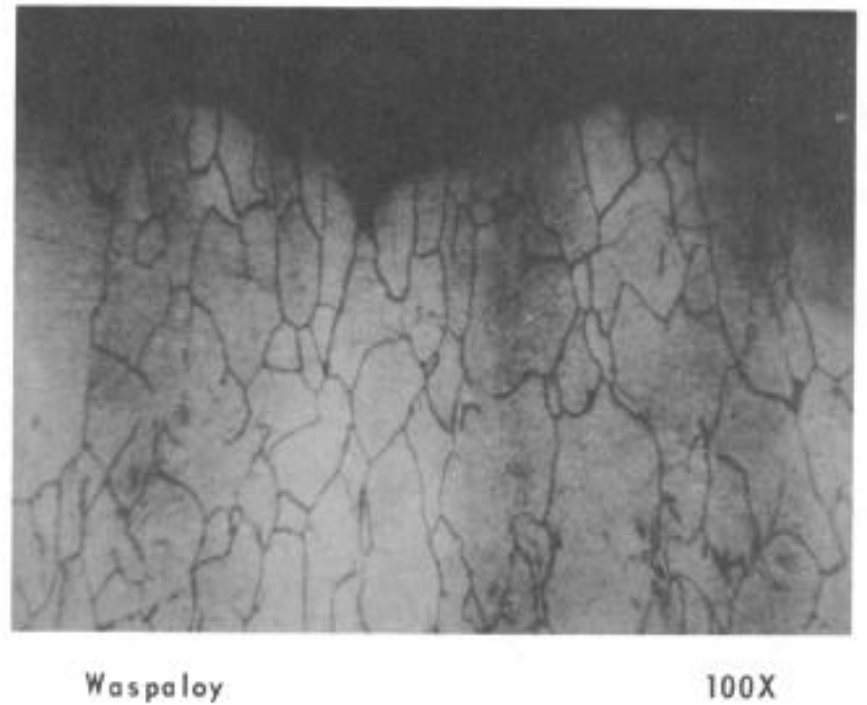

Electrolytic Etchant - $\mathrm{H}_{3} \mathrm{PO}_{4}+\mathrm{H}_{2} \mathrm{SO}_{4}+\mathrm{HNO}_{3}$

Longitudinal banding at tensile fracture revealed.
Tensile properties of obove:
$\frac{Y . S .}{128,000}$
$\frac{\text { T.S. }}{185,000}$
$\frac{\% \mathrm{EI} .}{26.5}$
$\%$ R.A.
35.2

FIGURE 4 


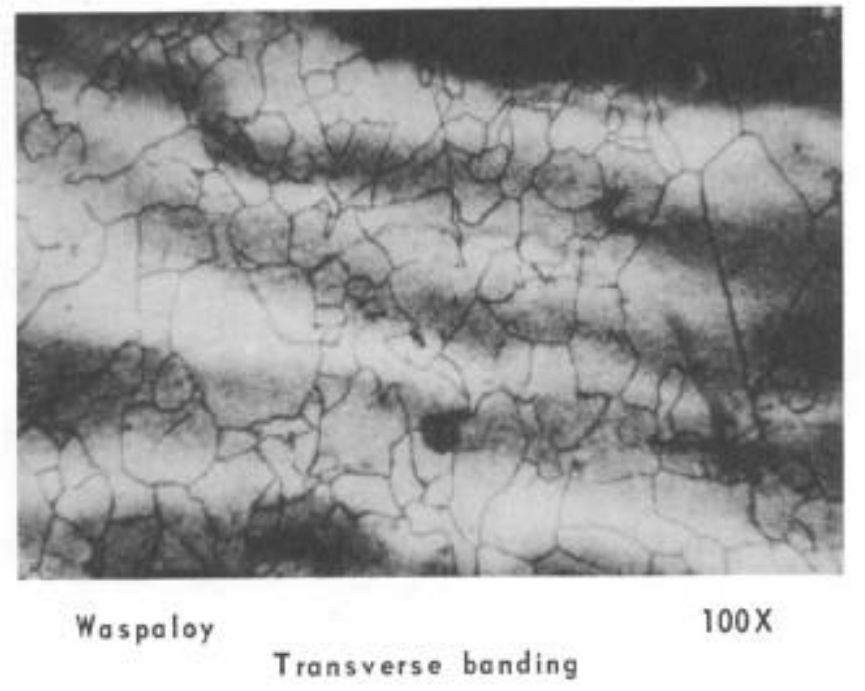

Tensile properties of above: $\quad \frac{\text { Y.S. }}{133,000} \quad \frac{\text { T.S. }}{167,000} \quad \frac{\% \text { EI. }}{8.0} \quad \frac{\% \text { R.A. }}{7.4}$

FIGURE 5 


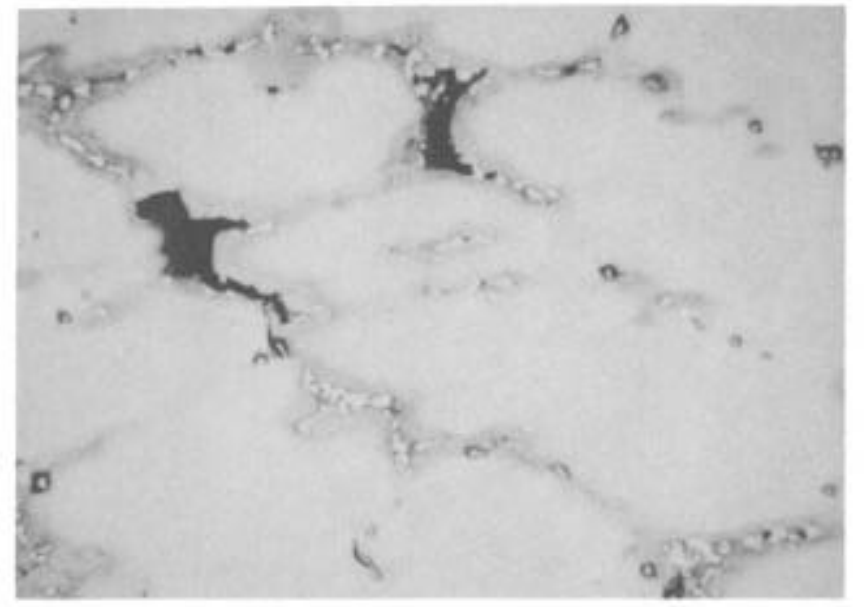

Inco 718 (etched)

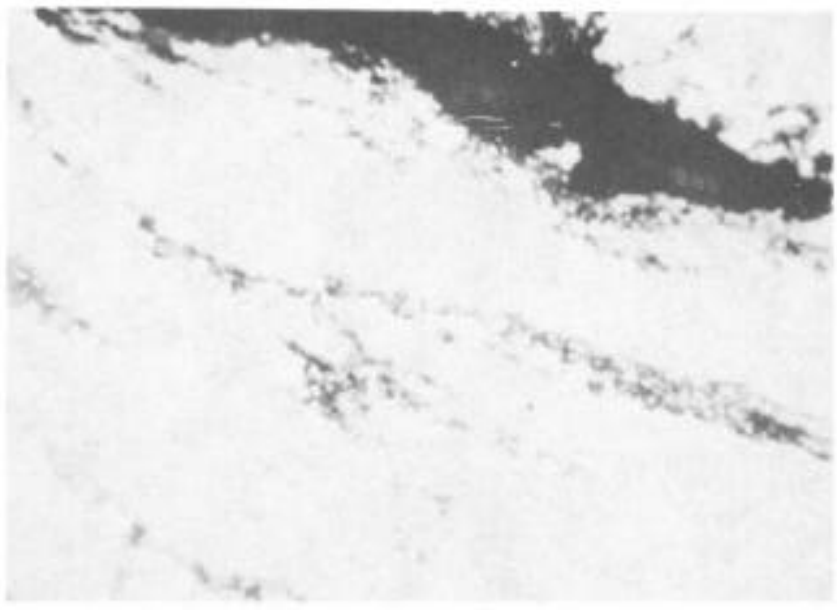

Waspaloy

$100 x$

Heavy titonium corbonitride and nitride stringers associated with rupturing.

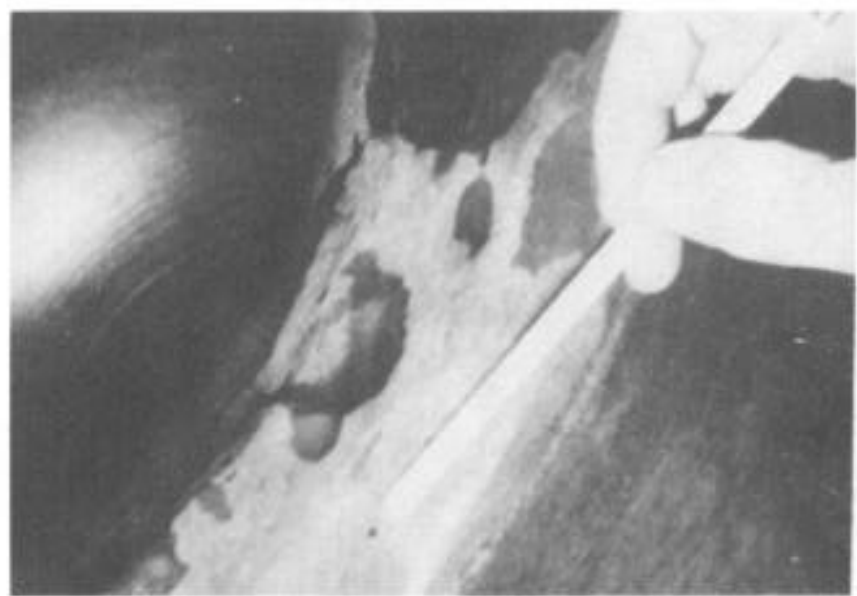

Waspaloy

$0.5 x$

Local face rupturing during forging of

Waspaloy case.

FIGURE 6 


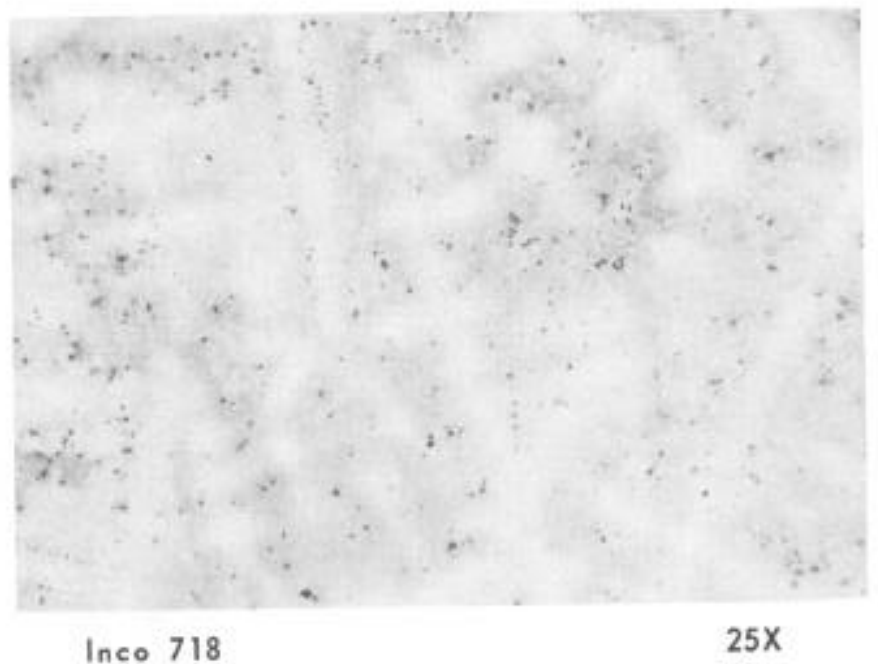

$2175^{\circ} \mathrm{F}, 12$ hours, air cool

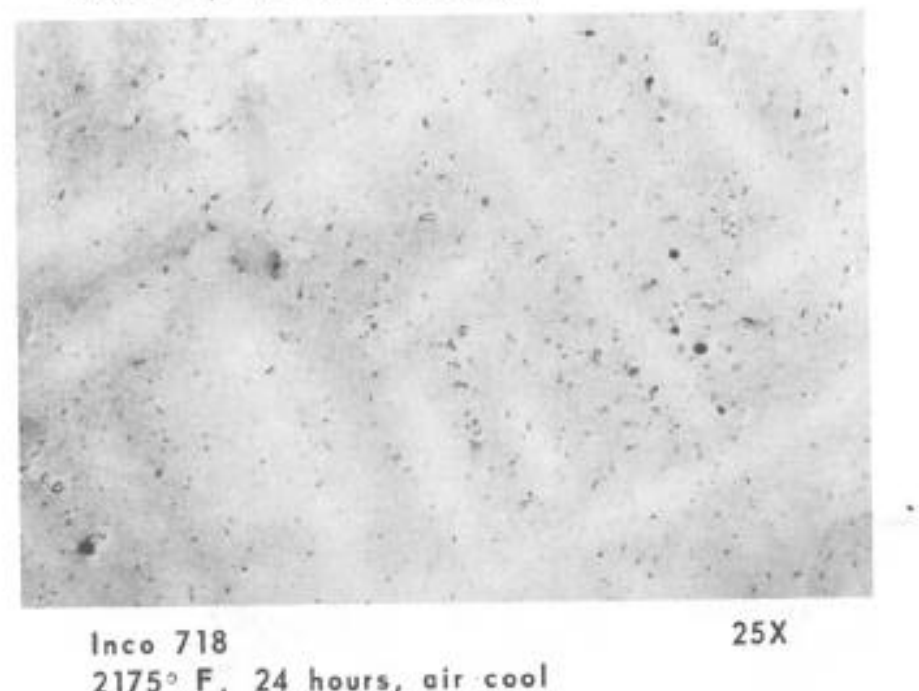

$2175^{\circ} \mathrm{F}, 24$ hours, air cool

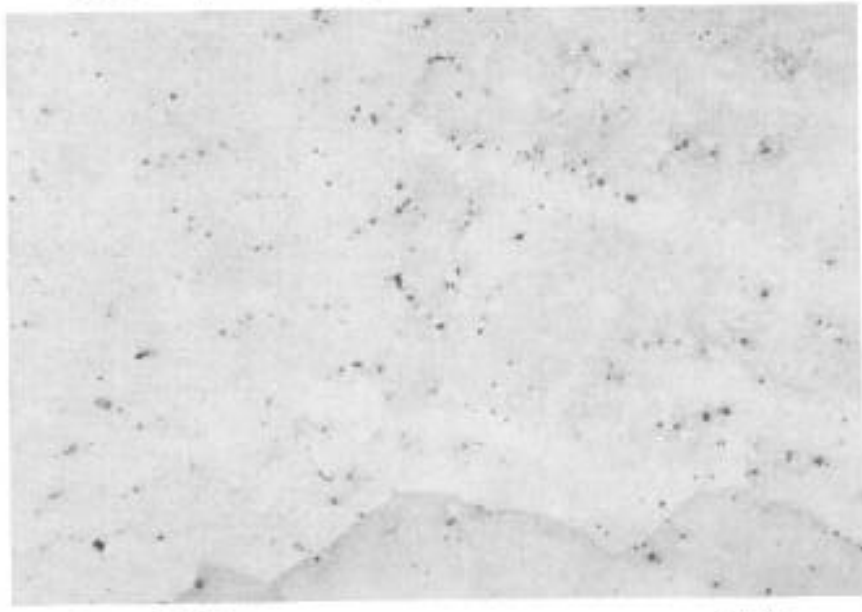

Inco 718

$2175^{\circ} \mathrm{F}, 36$ hours, air cool

FIGURE 7 
LADISH CO.

CLEANIINESS CLASSIFICATION OF HIGH TEMPERATURE ALLOYS

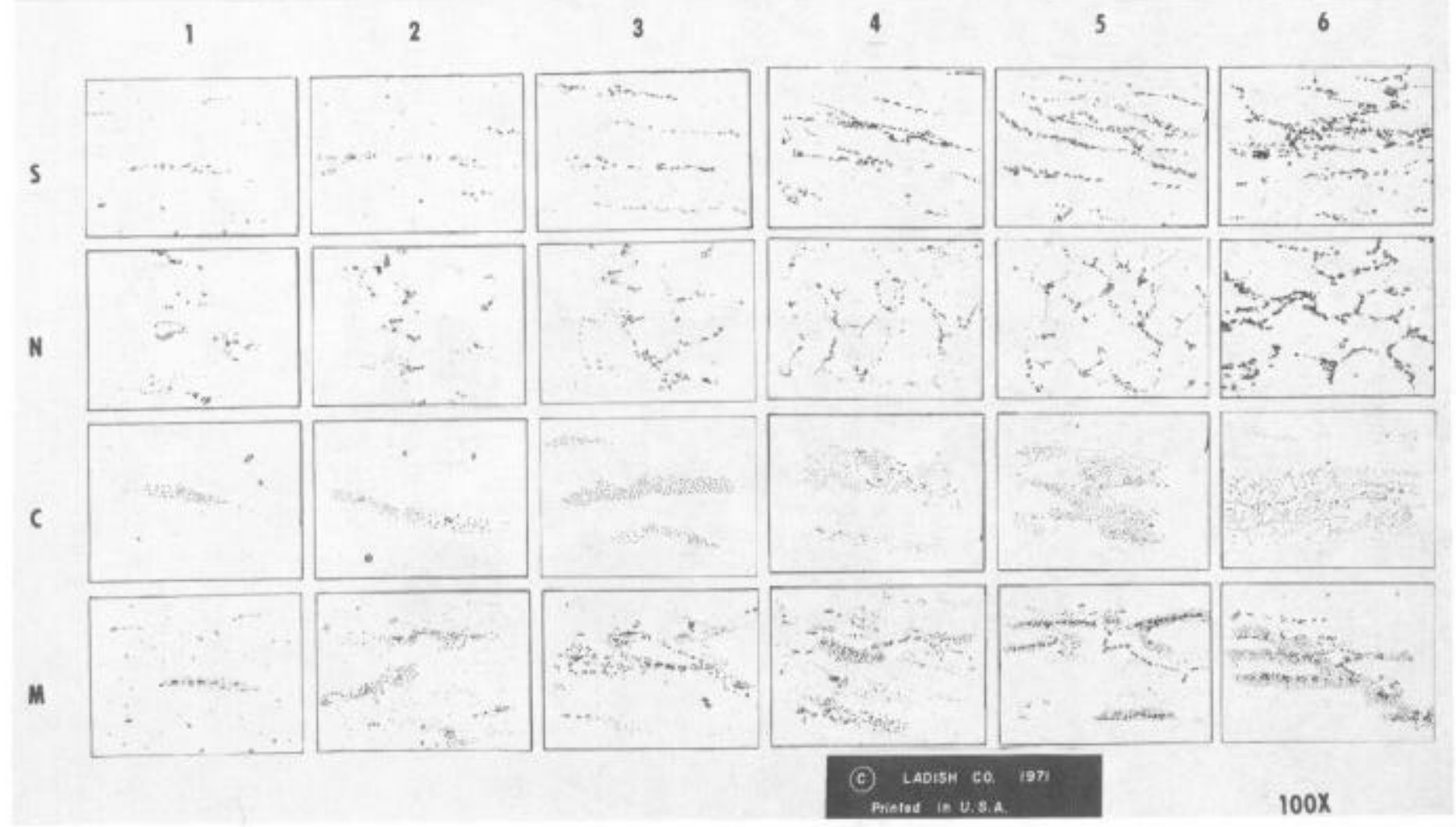

S - Intermetallic and/or metallic stringer segregation.

$\mathrm{N}$ - Intermetallic and/or metallic network segregation.

C - Intermetallic and/or metallic cluster segregation.

M - Intermetallic and/or metallic mixture - stringer, network and cluster segregation.

FIGURE 8 

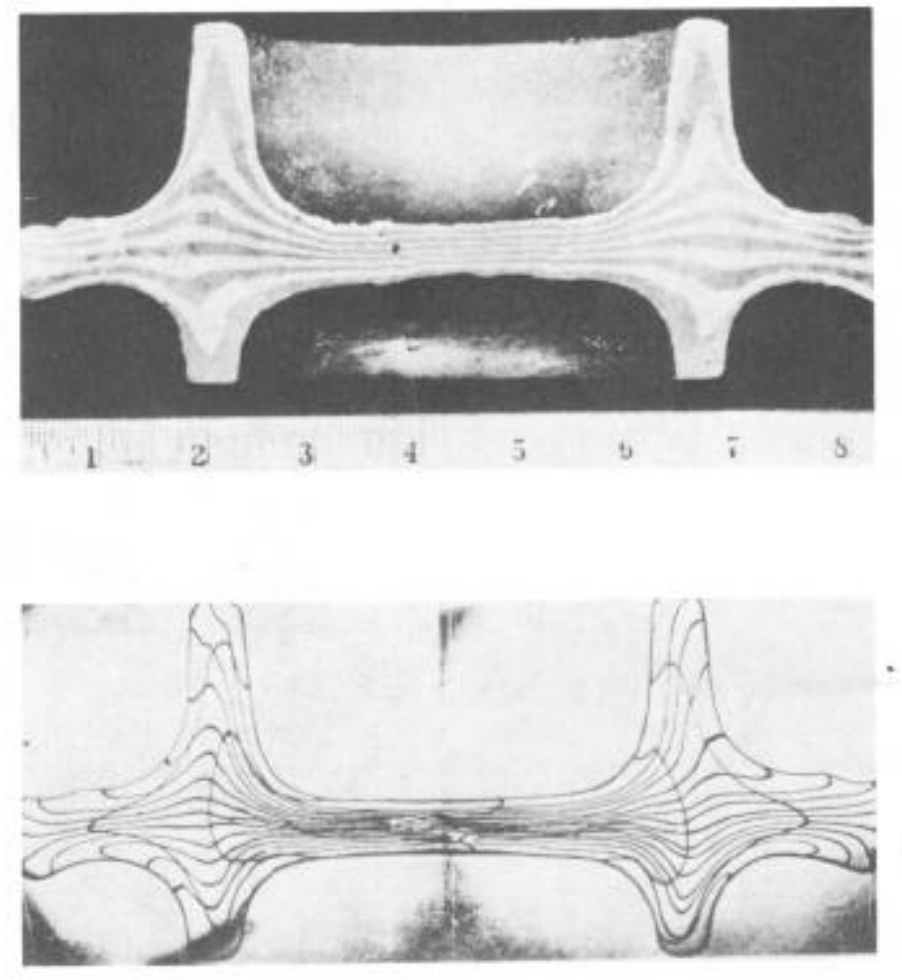

FIGURE 9 